\title{
Inflammatory bowel disease epidemiology in São Paulo State, Brazil
}

This article was published in the following Dove Press journal: Clinical and Experimental Gastroenterology

\author{
Rodrigo Galhardi Gasparini' \\ Ligia Yukie Sassaki² \\ Rogerio Saad-Hossne ${ }^{3}$ \\ 'Department of Digestive Surgery and \\ Gastroenterology, Sete Specialized \\ Medical Center, Marília, Brazil; \\ ${ }^{2}$ Department of Internal Medicine, \\ Botucatu Medical School at Sao Paulo \\ State University (UNESP), Botucatu, \\ Brazil; ${ }^{3}$ Department of Surgery, \\ Botucatu Medical School at Sao Paulo \\ State University (UNESP), Botucatu, \\ Brazil
}

Correspondence: Rodrigo Galhardi Gasparini

Department of Digestive Surgery and Gastroenterology, Sete Specialized Medical Center, Av Sete de Setembro 979, Marília, São Paulo 17502-020, Brazil Tel +55 I48137 792।

Email rodrigo@sete.med.br
Purpose: This study aimed to estimate the incidence and prevalence of inflammatory bowel disease (IBD) in São Paulo, Brazil, for 2012-2015.

Patients and methods: This observational, descriptive, and cross-sectional study included 22,638 IBD patients out of 43,046,555 inhabitants, who had initiated their treatment through the Governmental Program of the Brazilian Unified National Health System between the years of 2012 and 2015. The onset of the disease (used to determine incidence) was established as the date of the patient's initial registration in the Governmental Program with a diagnosis for Crohn's disease (CD) or ulcerative colitis (UC). Every patient registered in the system as of December 2015 was included in determining the prevalence. The demographic and clinical data, such as age and sex, were collected for each patient. Statistical analysis included mean and SD, absolute and percentage frequencies, and Pearson's chi-squared test $\left(\chi^{2}\right)$. The incidence and prevalence rates were calculated based on the estimated annual population of the State of São Paulo.

Results: The study population consisted of 10,451 (46.16\%) CD patients and 12,187 (53.84\%) UC patients. The mean age was 42.66 ( $\mathrm{SD} \pm 16.2$ ) years for the $\mathrm{CD}$ group and $47.87(\mathrm{SD} \pm 16.6)$ years for the UC group. There was a predominance of females corresponding to $59.70 \%$ of the study population (female:male $=1.48: 1.00 ; P<0.0001$ ). The incidence of IBD was 13.30 new cases $/ 100,000$ inhabitants per year, while the overall prevalence was 52.6 cases/100,000 inhabitants.

Conclusion: This population-based study demonstrated a stability in IBD incidence rates and an increase in IBD prevalence rates in São Paulo state between 2012 and 2015. The IBD incidence and prevalence rates were comparable to European countries, with a higher occurrence in the female participants

Keywords: inflammatory bowel disease, Crohn's disease, ulcerative colitis, epidemiology, incidence, prevalence

\section{Introduction}

Inflammatory bowel disease (IBD) is characterized by an inflammatory process that compromises the digestive tract, partially or totally. Ulcerative colitis (UC) and Crohn's disease $(C D)$ are its main representatives, with distinct and individual pathophysiological, clinical, and pathological characteristics. ${ }^{1-3}$ Although considered uncommon, IBD presents characteristics of chronicity, severity, evolution, and morbidity that significantly affect the quality of life of patients. ${ }^{1-3}$

Changes in the typical geographic distribution of IBD have been observed over the last years, with increasing rates of incidence and prevalence in regions with low incidence traditionally, such as Asia, South America, and Southern and Eastern Europe; 
as such, there has been an increase in the consideration of IBD as an emerging global disease ${ }^{4-6}$ Brazil has been considered as a country with low incidence and prevalence of IBD, although an evident increase in the number of appointments and hospitalizations of patients for IBD has occurred. ${ }^{7-9}$

There are few Brazilian epidemiological studies, possibly because there is no integrated diagnostic notification system, for IBD. Thus, the aim of this study was to estimate the incidence and prevalence rates of IBD in the State of São Paulo, the most populous in Brazil, between the years of 2012 and 2015, and analyze the patients' demographic characteristics.

\section{Patients and methods}

\section{Study design and population}

This observational, descriptive, and cross-sectional study included data from 22,638 patients who had initiated their treatment for IBD through the Governmental Program for free supply of high-cost medicines of the Brazilian Unified National Health System (SUS). All the patients registered in the program received salicylates and/or immunosuppressive and/or immunobiological drugs. No patient was excluded from the study.

The Governmental Program for free supply of high-cost medicines of the SUS is responsible for the coverage of $\sim 70 \%$ of the population. Data from private health insurance were not included in this study.

The moment of interest of the study was established as the date of initial registration in the Governmental Program of the patient with a diagnosis of CD or UC, with that date being defined as the date of disease onset. The clinical and demographic data, such as age and sex, were collected at that moment. For determining the prevalence, every patient registered in the system was included, regardless of their registration date. For determining the incidence, only patients whose initial registration occurred between January 2012 and December 2015 were included. All information presented herein was extracted from the computerized system of SUS for the State of São Paulo. The International Classification of Diseases codes K50 and K51 were used to identify CD and UC patients, respectively. ${ }^{10}$

All the data accessed from the SUS is de-identified in order to preserve the privacy and the identity of the studied population.

Quality of the present study was assessed with the Cochrane Collaboration-endorsed Newcastle-Ottawa Quality Assessment Scale (NOS), which was modified to assess aspects of quality relevant to population-based study of incidence. $^{11}$

\section{Data analyses}

The data collected were initially imported into the DBase III database for processing and tabulation, after which they were exported to spreadsheets in the Microsoft Excel program. Statistical analysis was conducted with analysis of mean and SD, for quantitative analysis, and absolute and percentage frequencies for qualitative variables. The Pearson's chisquared test $\left(\chi^{2}\right)$ of independence and adherence was used to analyze the qualitative variables and assess if the diseases followed a uniform distribution; mean estimate with a $99 \%$ confidence interval (CI 99\%). Significance was defined as $P<0.01$ for all tests.

The incidence and prevalence rates were calculated based on the estimated annual population of the State of São Paulo as follows: 41,939,997 inhabitants in $2012(20,409,123$ males and 21,530,874 females); 42,304,694 inhabitants in 2013 (20,586,963 males and 21,717,731 females); 42,673,386 inhabitants in $2014(20,766,532$ males and 21,906,854 females); and 43,046,555 inhabitants in 2015 (20,948,275 males and 22,098,280 females).

The annual correction of population growth estimated was $0.87 \% .^{12,13}$

\section{Ethical approval}

This study was approved by the Research Ethics Committee of the Universidade Estadual Paulista "Júlio de Mesquita Filho" (Protocol Number: 33401214.5.0000.5411).

\section{Results}

The study involved epidemiological data of 22,638 individuals out of a total of $43,046,555$ patients. CD patients comprised 10,451 (46.16\%) and UC patients comprised 12,187 $(53.84 \%)$ of the selected patients.

\section{Age}

The mean age of the overall study population was 45.5 ( $\mathrm{SD} \pm 16.7$ ) years, being $42.66(\mathrm{SD} \pm 16.2$ ) years for the $\mathrm{CD}$ patients and $47.87(\mathrm{SD} \pm 16.6)$ years for the UC patients. The distribution of patients according to age is shown in Figure 1.

\section{Sex}

There was a predominance of female sex, corresponding to $59.70 \%$ of the overall study population (female:male ratio $=1.48: 1.00 ; P<0.0001)$. The CD patients comprised 6,050 (57.9\%) females and 4,401 (42.1\%) males (female:male ratio $=1.37: 1.00 ; P<0.0001)$, while the UC patients comprised 7,464 (61.3\%) females and 4,723 (38.7\%) males (female:male ratio $=1.58: 1.00 ; P<0.0001$ ). 


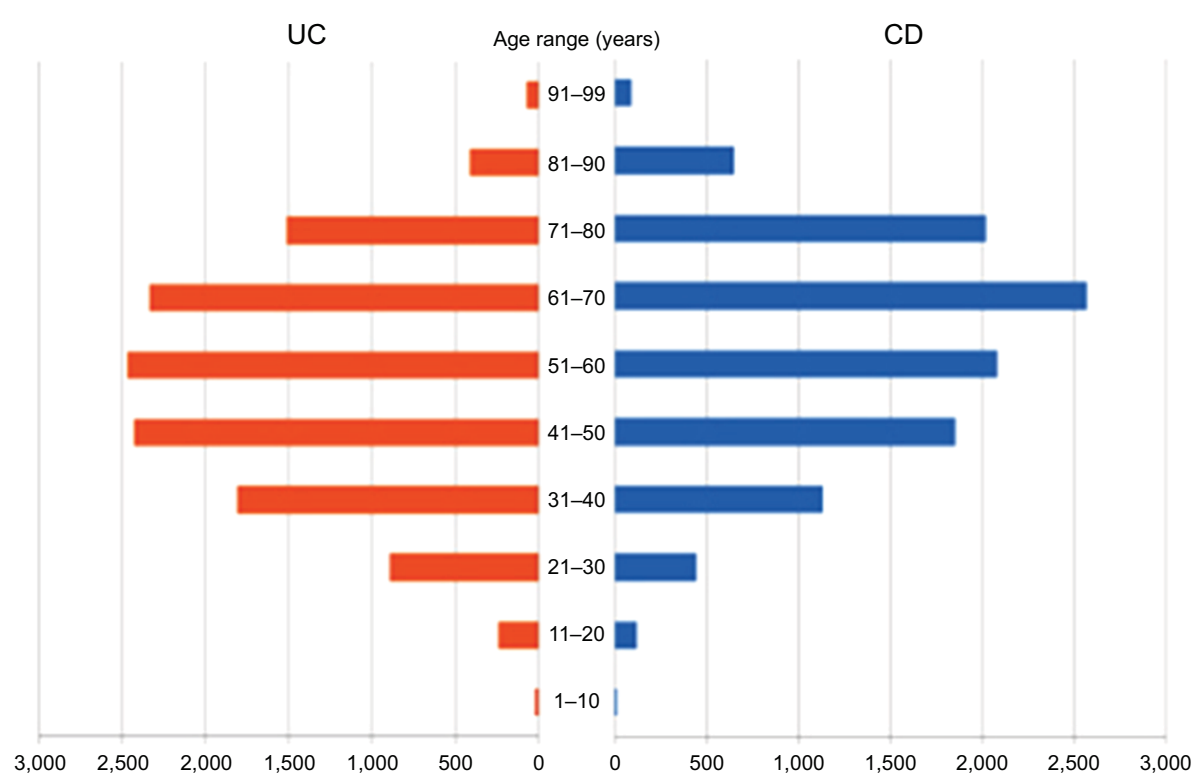

Figure I Distribution of patients with CD ( $n=10.45 \mathrm{I})$ and UC $(n=12.187)$ by age in the State of São Paulo (Brazil) for the period of $2012-2015$. Abbreviations: $C D$, Crohn's disease; UC, ulcerative colitis.

\section{Incidence and prevalence}

Incidence analyses of IBD cases, as well as CD and UC cases, between 2012 and 2015, are shown in Figures 2-4, respectively. The mean annual incidence of IBD was 13.30 new cases/100,000 inhabitants, considering incidence of $C D$ as 6.14 new cases/100,000 inhabitants/year (mean) and incidence of UC as 7.16 new cases/100,000 inhabitants/year (mean).

The prevalence rates of IBD, both in general and by specific diseases (CD and UC), are shown in Table 1.

\section{Discussion}

Brazil is considered as a country with low incidence and prevalence of IBD. ${ }^{7,14}$ Although national databases on incidence and prevalence of these diseases are deficient, there are data that indicate an increasing trend in the occurrence of IBD, even in the absence of precise information on new cases. ${ }^{14}$

São Paulo State is the most developed state in South America; its near 43 million inhabitants represent $21 \%$ of the entire Brazilian population and account for $28.7 \%$ of the Brazilian gross national product. About three million immigrants live in the state, coming from more than 70 different nations, and this demographic profile is representative of the overall Brazilian population. In addition, the state utilizes a fully computerized system for its Governmental Program providing the free supply of high-cost medicines, which allows for a safe parameterization of the obtained data. ${ }^{13}$

The SUS is considered to be one of the largest health systems in the world and was established through the Brazilian Federal Constitution of 1988, since the legislation itself contemplates the right to health for all citizens. The free supply of medication is included in the assistance provided by the SUS. ${ }^{15}$ About $71.1 \%$ of the national population uses the system, with $\sim 58 \%$ depending exclusively on it. The majority of IBD patients in Brazil obtain their drugs through the Governmental Program for providing the free supply of high-cost medicines, even with the increasing treatment of these patients in the private health system, which has been observed in recent years. ${ }^{15,16}$ Data from the private health insurance were not included in this study, which could either overestimate or underestimate the true incidence and prevalence rates. A study performed in Porto Rico showed the IBD prevalence was higher (61.75 cases) among commercial compared to government-sponsored managed health care insured individuals ( 14.36 cases). ${ }^{17}$

The slight drop in the incidence rates of $\mathrm{CD}$ observed in the study over the years can be explained by the drop in the number of patients enrolled in the Governmental Program in recent years. According to the present study, the incidence of CD was 6.14 new cases/100,000 inhabitants/year (mean) and the incidence of UC was 7.16 new cases/100,000 inhabitants/ year (mean). The prevalence rate was 24.3 cases $/ 100,000$ inhabitants for CD and 28.3 cases/100,000 inhabitants for UC. The IBD epidemiologic study by Victoria et al published in 2009 and conducted in the Midwestern region of the State of São Paulo demonstrated increases in the incidence between 1986 and 2005 (from 1.0 to 8.0 cases per 100,000 inhabitants) and in the prevalence (from 1.2 to 20.5 cases per 100,000 inhabitants), accounting for 5.6 cases $/ 100,000$ 


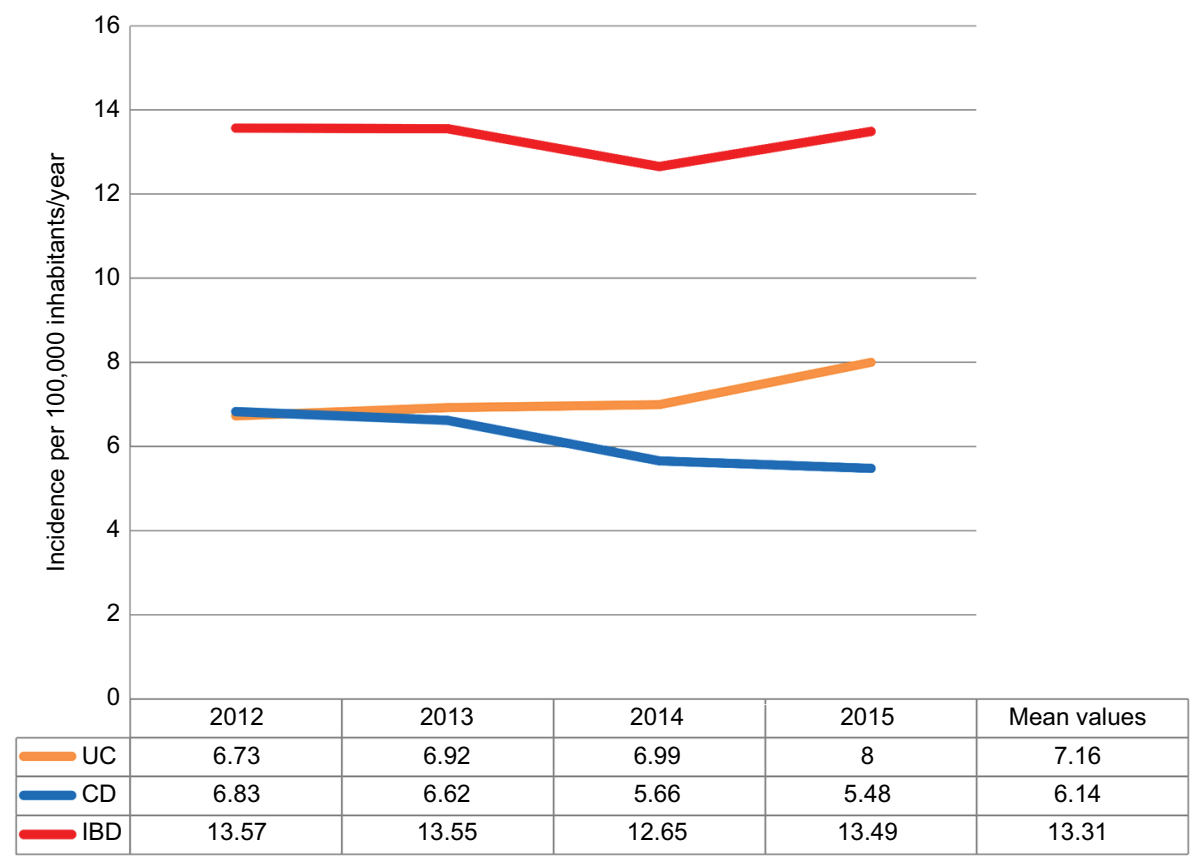

Figure 2 Annual incidence rates for IBD, CD, and UC in the State of São Paulo.

Note: Data are presented as new cases per 100,000 inhabitants/year.

Abbreviations: CD, Crohn's disease; IBD, inflammatory bowel disease; UC, ulcerative colitis.

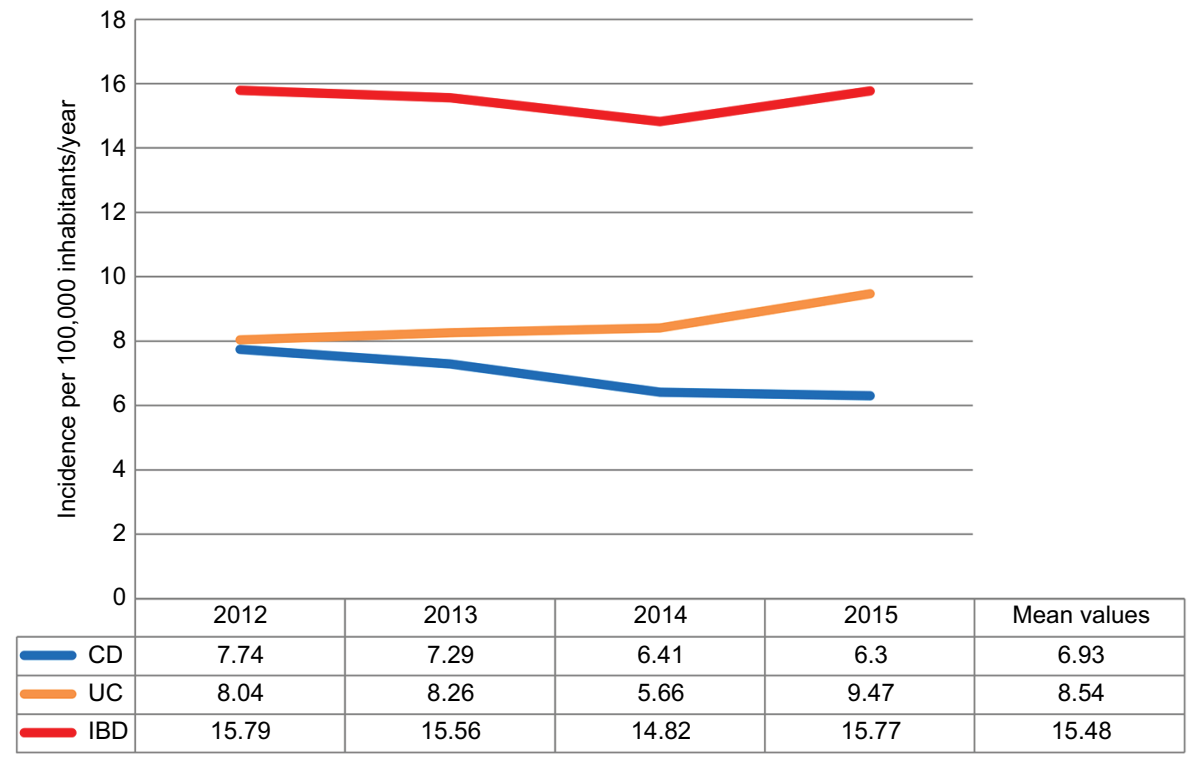

Figure 3 Annual incidences of IBD, CD, and UC among the female participants in the State of São Paulo for the period of 20I2-2015.

Notes: Data are presented as new cases per 100,000 inhabitants/year.

Abbreviations: CD, Crohn's disease; IBD, inflammatory bowel disease; UC, ulcerative colitis.

inhabitants for CD and 14.8 cases/100,000 inhabitants for UC. ${ }^{7}$ Comparatively, we also observed a significant increase in the rates of incidence of CD and UC between 2012 and 2015. The rate of prevalence of IBD detected in this study, being 52.6 cases/100,000 inhabitants, suggests a growing trend for these diseases in the State of São Paulo.
The numbers determined in the present study are higher than those presented for Brazil in the systematic review by $\mathrm{Ng}$ et al, which demonstrated an incidence of CD from 0.81 to 1.94 new cases $/ 100,000$ inhabitants/year and an incidence of UC from 1.86 to 3.09 new cases/100,000 inhabitants/ year. Concerning the prevalence, our data are also higher 


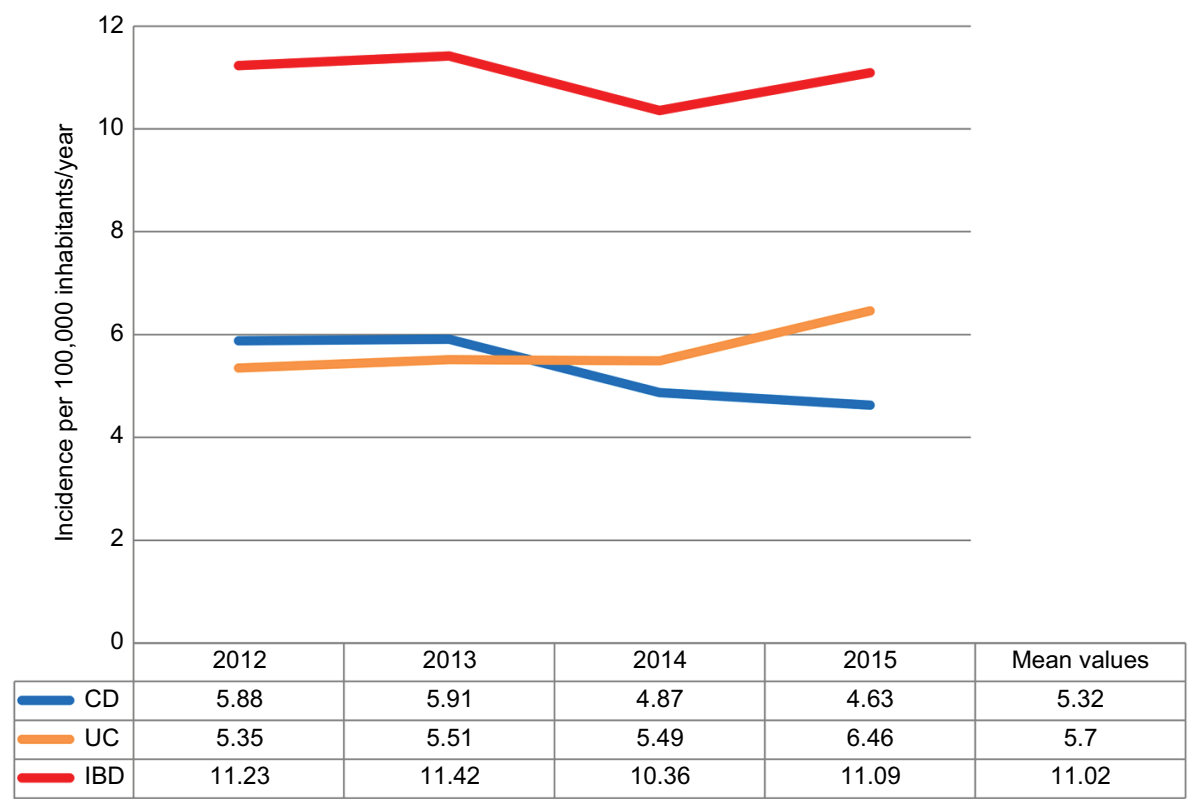

Figure 4 Annual incidences of IBD, CD, and UC among the male participants in the State of São Paulo for the period of 20I2-20I5. Note: Data are presented as new cases per 100,000 inhabitants/year.

Abbreviations: $C D$, Crohn's disease; IBD, inflammatory bowel disease; UC, ulcerative colitis.

Table I Prevalence of IBD in the State of São Paulo in December 2015

\begin{tabular}{|l|l|l|l|}
\hline & CD & UC & Total \\
\hline Male & 21.0 & 22.5 & 43.5 \\
Female & 27.4 & 33.8 & 61.1 \\
Total & 24.3 & 28.3 & 52.6 \\
\hline
\end{tabular}

Note: Data are presented as new cases per 100,000 inhabitants.

Abbreviations: CD, Crohn's disease; IBD, inflammatory bowel disease; UC, ulcerative colitis.

to those reported by $\mathrm{Ng}$ et al, which varied from 0.6 to 6.75 cases/100,000 inhabitants for CD and from 2.42 to 21 cases/100,000 inhabitants for UC. ${ }^{18}$

The incidence rate for CD in North America is over 6.38 new cases/100,000 inhabitants/year and for UC is over 7.71 new cases/100,000 inhabitants/year; these are similar to the rates for São Paulo determined in the present study. However, the North American prevalence rates greatly exceed the ones observed in our study, which show over 135.6 cases/100,000 inhabitants for CD and higher than the 198 cases/100,000 inhabitants for UC. ${ }^{18}$

The results of the present study show incidence rates of IBD in São Paulo comparable to European countries, such as Israel (13.2 new cases/100,000 inhabitants/year), Czech Republic (12.2 new cases/100,000 inhabitants/year), Portugal (11.1 new cases/100,000 inhabitants/year), and Ireland (13.2 new cases/100,000 inhabitants/year). The prevalence of $\mathrm{CD}$ was $1.5-213$ cases per 100,000 inhabitants and that of UC was 2.4-294 cases per 100,000 inhabitants in these countries. ${ }^{19,20}$

There is little information on IBD epidemiology in Latin America, with data from countries such as Argentina, Uruguay, Puerto Rico, and Mexico referring to the beginning of the $21 \mathrm{st}$ century in particular. Those published rates are lower than those found in the present study, with incidence of UC between 2.2 and 4.3 new cases/100,000 inhabitants/year and of CD between 0.8 and 2.0 new cases/100,000 inhabitants/year. ${ }^{21,22}$ Despite the low prevalence of IBD in São Paulo, as compared to North America and Europe, the similarity of incidence rates allows us to infer that sometime in the future the prevalence data may equalize, considering the trend toward stabilization or even reduction of the incidence rates of IBD in developed countries that was demonstrated in the systematic review of $\mathrm{Ng}$ et al. ${ }^{18}$

The data of the present study and previous studies related to the epidemiology of IBD in Brazil are demonstrated in Table 2.

Regarding age, the results of the present study show an evident prevalence of IBD in individuals between 20 and 50 years. In the group of patients with UC, there was a tendency toward an increase in incidence among patients over 60 years old. Such results are indistinct from the ones obtained in other Brazilian studies, such as those by Silva and Souza et al, and international studies, such as those by Burisch and Munkholm and Chouraki et al. ${ }^{8,14,19,23}$ We admit, however, that delay in the diagnosis of IBD can influence the outcome of the incidence distribution by age groups. In a recent study undertaken in the Northeast region of Brazil, a delay of up to 28.2 months was 
Table 2 Data from the present study and from the previous studies related to the IBD epidemiology in Brazil

\begin{tabular}{|l|l|l|l|l|}
\hline \multirow{2}{*}{ Studies } & \multicolumn{2}{|l|}{ CD } & UC \\
\cline { 2 - 5 } & Incidence & Prevalence & Incidence & Prevalence \\
\hline Victoria et al (2009)7 & 3.5 & 5.65 & 4.48 & 14.81 \\
Molodecky et al (2012) & $1.95-3.76$ & $25.1-48$ & $3.10-4.97$ & $44.4-100.9$ \\
Ng et al (20I7) & $0.81-1.94$ & $0.6-6.75$ & $1.86-3.09$ & $2.42-21$ \\
São Paulo State (São Paulo State - 2018) & 6.11 & 24.5 & 7.13 & 28.5 \\
\hline
\end{tabular}

Notes: Incidence is presented as new cases per 100,000 inhabitants/year. Prevalence is presented as new cases per 100,000 inhabitants.

Abbreviations: CD, Crohn's disease; UC, ulcerative colitis.

observed between the beginning of the clinical manifestations and the diagnostic confirmation of IBD. ${ }^{24}$

The results of the present study demonstrated a greater prevalence of IBD among female participants, both for CD and UC. Similar results were observed in studies of other regions of Brazil as well as in Chile, and in the systematic review by Hovde and Moum..$^{1,7,14,25,26}$ A recent Brazilian study demonstrated that males seek less health services (63.9\%) than females $(78 \%)$, demonstrating that cultural factors may influence this result. ${ }^{27}$

The self-reported ethnic group was also evaluated in the study population, with results showing a predominance of the ethnic group self-declared Caucasian (19\%), followed by the ethnic group self-declared mixed race $(0.3 \%)$, African descent $(0.1 \%)$, oriental descent $(0.25 \%)$, and indigenous $(0.17 \%)$, and there was no statistically significant difference between $\mathrm{CD}$ and UC patients. These results show ethnic data comparable to those obtained in 2007 from the city of São Paulo, in the POLI study, which demonstrates a predominance of the group self-declared Caucasian (68.9\%), followed by the African descent group (7.8\%), mixed race (1.5\%), oriental descent $(1.5 \%)$, and indigenous $(0.5 \%){ }^{28}$

In this study, however, $77 \%$ of the patients did not declare their ethnic background, making the ethnicity data of the present study only illustrative. The present study is the first in Brazil regarding incidence and prevalence of IBD in a large sample and represents real-life data from a regional population. According to the Cochrane Collaborationendorsed NOS, our study can be classified as representative of the target population. ${ }^{11}$ Limitations of this study were the non-inclusion of all patients with IBD in Brazil and the lack of other clinical data, such as medications in use, and other data concerning the disease, such as disease extension and presence of complications.

\section{Conclusion}

According to the study design and applied methodology, there was a stability in IBD incidence rates and an increase in the
IBD prevalence rates in São Paulo state between 2012 and 2015, with a small decrease in CD rates and an increase in UC rates according to SUS data, but with a significant increase in these rates compared to previous studies. The age groups between 20 and 60 years had the highest rates of incidence and prevalence. A higher occurrence was observed in females for both CD and UC. This study also shows that there is much to be explored in relation to the epidemiology of IBD in Brazil, and it is essential for the development of broader surveys that better define the national rates of IBD incidence and prevalence.

\section{Disclosure}

The authors report no conflicts of interest in this work.

\section{References}

1. Figueroa CC, Quera PR, Valenzuela EJ, Jensen BC. [Diseases intestinal inflammations: Experience of two Chilean centers] Enfermedades inflamatorias intestinales: Experiencia de dos centros chilenos. Revista médica de Chile. 2005;133(11):1295-1304. Spanish.

2. Cardozo WS, Sobrado CW. Doença Inflamatória Intestinal. 2 ed. Barueri-SP: Manole; 2015.

3. Barbalho SM, Goulart RA, Gasparini RG. Associations between inflammatory bowel diseases and vitamin D. Crit Rev Food Sci Nutr. 2017;13:1-10.

4. Bernstein CN, Shanahan F. Disorders of a modern lifestyle: reconciling the epidemiology of inflammatory bowel diseases. Gut. 2008;57(9):1185-1191.

5. Goh K, Xiao SD. Inflammatory bowel disease: a survey of the epidemiology in Asia. J Dig Dis. 2009;10(1):1-6.

6. Molodecky NA, Soon IS, Rabi DM, et al. Increasing incidence and prevalence of the inflammatory bowel diseases with time, based on systematic review. Gastroenterology. 2012;142(1):46-54.e42; quiz e30.

7. Victoria CR, Sassak LY, Nunes HR. Incidence and prevalence rates of inflammatory bowel diseases, in midwestern of São Paulo State, Brazil. Arq Gastroenterol. 2009;46(1):20-25.

8. da Silva BC, Lyra AC, Mendes CM. The Demographic and Clinical Characteristics of Ulcerative Colitis in a Northeast Brazilian Population. Biomed Res Int. 2015;2015:359130.

9. Kleinubing-Júnior H, Pinho Mdesl, Ferreira LC, Bachtold GA, Merki A. [Profile of outpatients with inflammatory bowel diseases] Perfil dos pacientes ambulatoriais com doenças inflamatórias intestinais. $A B C D$. Arquivos Brasileiros de Cirurgia Digestiva. 2011;24(3):200-203. Portugese.

10. Saúde OMda. [ICD-10 International Statistical Classification of Diseases and Related Health Issues] CID-10 Classificação Estatística Internacional de Doenças e Problemas Relacionados Saúde. 10a rev. São Paulo: Universidade de São Paulo; 1997. Portugese. 
11. Wells GA, Shea B, O'Connell D. The Newcastle-Ottawa Scale (NOS) for assessing the quality of nonrandomised studies in meta-analyses; 2014. Available from: http://www.ohri.ca/programs/clinical_epidemiology/oxford.asp. August 02, 2018.

12. Instituto Brasileiro de Geografia e Estatística (IBGE). Censo; 2010. Available from: http://censo2010.ibge.gov.br. November 25, 2017.

13. Fundação Sistema Estadual de Análise de Dados (SEADE). Portal de Estatísticas do Estado de São Paulo. Available from: http://www. seade. gov.br. November 25, 2017.

14. Souza MH, Troncon LE, Rodrigues CM, et al. [Evolution of the occurrence (1980-1999) of Crohn's disease and rectocolitis idiopathic ulcer disease and analysis of its clinical features in a university hospital in southeastern Brazil] Evolução da ocorrência (1980-1999) da doença de Crohn e da retocolite ulcerativa idiopática e análise das suas características clínicas em um hospital universitário do sudeste do Brasil Arq Gastroenterol. 2002;39(2):98-105. Portuguese.

15. Instituto Brasileiro de Geografia e Estatística (IBGE). 2015. Available from: http://www.ibge.gov.br. December 06, 2018

16. Instituto de Pesquisa Econômica Aplicada (IPEA). Available from: http://www.ipea.gov.br. December 06, 2018.

17. Vendrell R, Venegas HL, Pérez CM, Morell C, Roman RV, Torres EA. Differences in prevalence of inflammatory bowel disease in Puerto Rico between commercial and government-sponsored managed health care insured individuals. Bol Asoc Med P R. 2013;105(2):15-19.

18. Ng SC, Shi HY, Hamidi N, et al. Worldwide incidence and prevalence of inflammatory bowel disease in the 21 st century: a systematic review of population-based studies. Lancet. 2018;390(10114):2769-2778.

19. Burisch J, Munkholm P. Inflammatory bowel disease epidemiology. Curr Opin Gastroenterol. 2013;29(4):357-362.

20. Burisch J, Pedersen N, Č uković-Čavka S, et al; EpiCom-group. EastWest gradient in the incidence of inflammatory bowel disease in Europe: the ECCO-EpiCom inception cohort. Gut. 2014;63(4):588-597.
21. Farrukh A, Mayberry JF. Inflammatory bowel disease in Hispanic communities: a concerted South American approach could identify the aetiology of Crohn's disease and ulcerative colitis. Arq Gastroenterol. 2014;51(4):271-275.

22. Kotze PG. Research in inflammatory bowel diseases in Latin America: a challenge ahead. Arq Gastroenterol. 2014;51(4):269-270.

23. Chouraki V, Savoye G, Dauchet L, et al. The changing pattern of Crohn's disease incidence in northern France: a continuing increase in the 10- to 19-year-old age bracket (1988-2007). Aliment Pharmacol Ther. 2011;33(10):1133-1142.

24. Parente JM, Coy CS, Campelo V, et al. Inflammatory bowel disease in an underdeveloped region of Northeastern Brazil. World J Gastroenterol. 2015;21(4):1197-1206.

25. Souza MM, Belasco AGS, Aguilar-Nascimento JE. [Epidemiological profile of patients with inflammatory bowel disease of the state of Mato Grosso] Perfil epidemiológico dos pacientes portadores de doença inflamatória intestinal do estado de Mato Grosso. Rev Bras. Colo-proctol. 2008;28(3):324-328. Portuguese.

26. Hovde $\varnothing$, Moum BA. Epidemiology and clinical course of Crohn's disease: results from observational studies. World $J$ Gastroenterol. 2012;18(15):1723-1731.

27. Gomes R, Nascimento EF, Araújo FC. [Why do men use health services less than women? Explanations by men with low versus higher education]. Por que os homens usam os serviços de saúde? menos que as mulheres? Explicações de homens com baixa versus alta escolaridade. Cad. Saúde Pública. 2007;23(3):565-574. Portuguese.

28. Poli DD. Impacto da ancestralidade na apresentação e evolução da doença de Crohn no Brasil. São PauloUniversidade de São Paulo: Faculdade de medicina; 2007.
Clinical and Experimental Gastroenterology

\section{Publish your work in this journal}

Clinical and Experimental Gastroenterology is an international, peerreviewed, open access, online journal publishing original research, reports, editorials, reviews and commentaries on all aspects of gastroenterology in the clinic and laboratory. This journal is included on PubMed. The manuscript management system is completely online

\section{Dovepress}

and includes a very quick and fair peer-review system, which is all easy to use. Visit http://www.dovepress.com/testimonials.php to read real quotes from published authors. 